\title{
INVESTIGATION OF OROFACIAL STEM CELL NICHES AND THEIR INNERVATION THROUGH MICROFLUIDIC DEVICES
}

\author{
P. Pagella ${ }^{1}$, E. Neto ${ }^{2,3}$, M. Lamghari ${ }^{2,4}$ and T.A. Mitsiadis ${ }^{1 *}$ \\ ${ }^{1}$ Orofacial Development and Regeneration, Institute of Oral Biology, Centre for Dental Medicine, \\ University of Zurich, Zurich, Switzerland. \\ ${ }^{2}$ INEB - Instituto de Engenharia Biomédica, Universidade do Porto, Porto, Portugal \\ ${ }^{3}$ FMUP - Faculdade de Medicina da Universidade do Porto, Porto, Portugal \\ ${ }^{4}$ ICBAS - Instituto de Ciências Biomédicas Abel Salazar, Universidade do Porto, Porto, Portugal
}

\begin{abstract}
Stem cell-based mediated therapies represent very promising approaches for tissue regeneration and are already applied with success in clinics. These therapeutic approaches consist of the in vitro manipulation of stem cells and their consequent administration to patients as living and dynamic biological agents. Nevertheless, the deregulation of stem cells function might result in the generation of pathologies such as tumours or accelerated senescence. Moreover, different stem cells sources are needed for regeneration of specific tissues. It is thus fundamental to understand the mechanisms regulating the physiology of stem cells. Microfluidic technology can be used to mimic in vivo scenarios and allow the study of stem cell physiology at both single cell and whole stem cell niche levels. This review focuses on the potential sources of stem and progenitor cells for orofacial regeneration and the use of microfluidic technologies for the study of stem cells behaviour and stem cell niches, in the light of regenerative medicine.
\end{abstract}

Keywords: Microfluidics, stem cells, stem cell niches, orofacial regeneration, tooth, innervation, trigeminal ganglia, regenerative medicine.

*Address for correspondence:

Prof. Thimios A. Mitsiadis

Orofacial Development \& Regeneration Division

Institute of Oral Biology, Centre for Dental Medicine, Faculty of Medicine

University of Zurich, Plattenstrasse 11, 8032 Zurich, Switzerland

Telephone number: +41446343390

Fax number: +41446344314

E-mail: thimios.mitsiadis@zzm.uzh.ch

\section{Introduction}

The development of organs and tissues that belong to the orofacial complex proceeds through a series of inductive interactions between cells originated from the epithelium, mesoderm and cranial neural crest-derived mesenchyme (Mao et al., 2012; Mitsiadis and Graf, 2009; Mitsiadis and Papagerakis, 2011). Orofacial organs are highly diverse and exert fundamental and specific functions such as breathing, chewing, speech, smell, and sight (Mao et al., 2012). The physiological functions of these organs are compromised by traumatic injuries, congenital and infectious diseases, and cancer (Mao et al., 2012; Scheller et al., 2009). Furthermore, these pathologies are often accompanied by intensive pain and aesthetic deformities. Therefore, the treatment of compromised pathological orofacial tissues and organs should guarantee restoration of both functionality and aesthetics, which constitutes an enormous clinical challenge. Moreover, organ structure, function, aesthetics, and pain should be managed simultaneously during the regenerative care, a situation that is more complex than in other compartments of the body (Scheller et al., 2009).

Biological regeneration is proving an increasingly attractive alternative and complement to traditional surgical techniques for prosthetic replacement of tissues and organs. Cell-based therapeutic approaches are already applied with success in clinics and consist of in vitro manipulation of stem cells and their consequent administration to patients as living and dynamic biological agents. Stem cells are characterised by their potential to self-replicate and their capacity to differentiate into a vast variety of cell types that form the diverse tissues. Therefore, stem cells guarantee tissue repair and regeneration throughout life. During the last decades, a plethora of adult stem cell populations have been isolated from different locations of orofacial organs, characterised, and tested for their potential applications in regenerative medicine (Mao et al., 2012; Mitsiadis et al., 2012; La Noce et al., 2014). Adult stem cells could be removed from a patient, expanded and placed back into the same individual when tissue repair becomes necessary, thereby removing the need for immunosuppression (Mitsiadis et al., 2007; Mitsiadis et al., 2012).

The decision between stem cell renewal and differentiation is influenced by a specialised microenvironment, the stem cell niche. The particular microenvironment of niches may regulate how the various stem cell populations participate in maintenance, repair and regeneration of the orofacial tissues and organs. Specific signals derived from precise areas of the niche permit stem 


\section{placode}

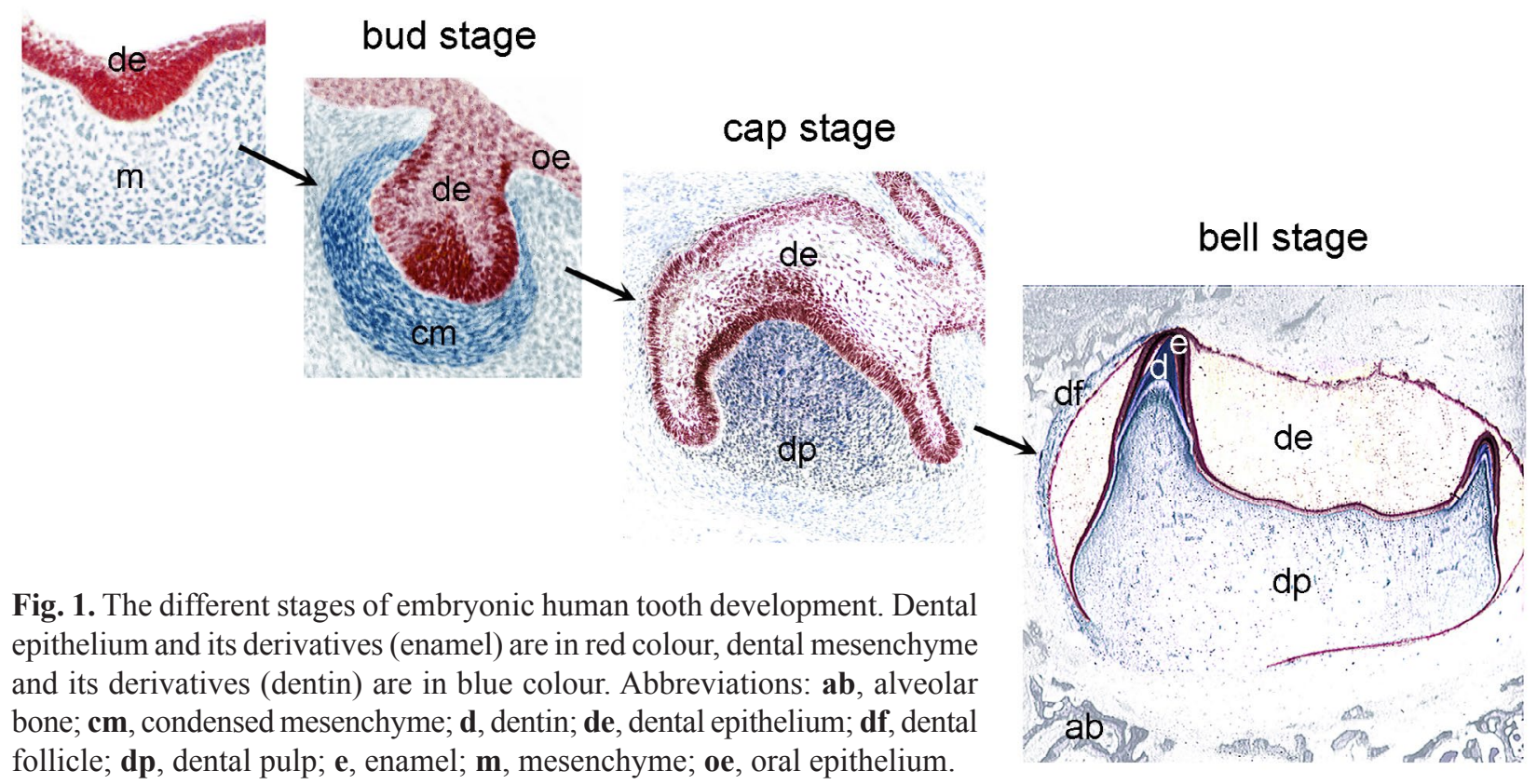

cells to stay alive, to change their number and fate (Djouad et al., 2009; Scadden, 2006). Soluble molecules such as the Wnt, Notch, and fibroblast growth factors (FGFs) are important paracrine regulators of stem cell function (Mitsiadis et al., 2007). The function of adult stem cells is often limited outside the niche and its deregulation might result in the generation of pathologies such as tumours or accelerated tissue senescence. It is thus fundamental to identify and understand the exact mechanisms that regulate the physiology of stem cells. The long-term exposure to soluble factors and the application of physical stimuli is crucial when investigating essential properties of stem cells.

The combination of microfluidic technologies with stem cell biology has laid the development of advanced in vitro systems capable of analysing cell cultures under physiologically relevant conditions (Ertl et al., 2014). Microfluidic devices are currently used for studying stem cells and their niches, as well as the various molecules that influence stem cell behaviour (Titmarsh et al., 2014). This technology could deliver important information on stem cell behaviour under controlled and reproducible measurement conditions (Whitesides, 2006). Microfluidic systems provide spatial and temporal control over stem cell function and fate by combining extracellular matrix geometries with microfluidic channels that regulate the transport of soluble factors.

This review focuses on the synergistic effects of stem cells and neurons during homeostasis and regeneration of orofacial tissues. In this perspective, we first present an overview of orofacial development and pathology. We then discuss about the various stem cell populations within the orofacial complex that could be used for organ regeneration. Thereafter, we report on the importance of stem cell niches in cell and tissue physiology. Finally, we focus our attention on microfluidic technologies that can be applied for the modelling of stem cell niches.
Development and pathology of the orofacial complex The orofacial complex develops from four processes: the frontal, the mandibular, and the two maxillary processes. Each process comprises an epithelial layer and a group of mesodermal and cranial neural crest-derived cells (CNCCs). CNCCs originate from the dorsal edges of the folding neural plate, and their intermingling with the paraxial mesoderm form the mesenchyme of the facial prominences. The mesoderm gives rise to the jaw musculature, while CNCC-derived mesenchyme forms the bones, cartilage, connective tissues and all organs (e.g. teeth, salivary glands) of the orofacial area (Minoux and Rijli, 2010; Mitsiadis, 2011). The development of these organs relies on successive reciprocal interactions between epithelial and mesenchymal cells (Handrigan et al., 2007; Mitsiadis and Graf, 2009). Inappropriate signalling could alter these tissue-tissue interactions, thus resulting in orofacial malformations, which account for approximately one-third of all birth defects (Dixon et al., 2011; Kouskoura et al., 2011). For example, a common orofacial birth defect manifestation is the cleft palate (CP), which is caused by a failure in palatal shelves fusion due to genetic mutations and/or environmental influences (Cobourne, 2004; Kouskoura et al., 2011). The incidence of these birth defects in the Caucasian population is approximately 1:800-1:1.000 live births (Bonaiti et al., 1982; Cobourne, 2004). Clefts require long-term complex treatments and often have lifelong implications. Surgery is the only treatment available, consisting in fatal intrauterine palate closure or postnatal palate closure or bone grafting (Goodacre and Swan, 2008; Papadopoulos et al., 2005).

Teeth are the most studied organs of the orofacial complex. Teeth are derived from CNCC-derived mesenchyme and epithelium of the first branchial arch and a part of the frontonasal process (Cobourne and Mitsiadis, 2006; Mitsiadis and Luder, 2011). Similarly to the development of other organs that form as epithelial 
appendages (e.g. hairs, whiskers, glands), tooth growth proceeds in morphologically distinct stages (Fig. 1). Odontogenesis starts with epithelial thickenings at the sites of the future dental arches in the maxilla and mandible, which are called the dental placodes. Subsequent features of odontogenesis include the budding of the epithelium and the concomitant mesenchymal condensation, the continuous folding of the epithelium, and finally the differentiation of dental mesenchymal and epithelial cells into the dentin producing odontoblasts and the enamel forming ameloblasts, respectively (Cobourne and Mitsiadis, 2006; Lumsden, 1988; Mitsiadis and Graf, 2009; Mitsiadis and Luder, 2011). A series of sequential and reciprocal epithelial-mesenchymal interactions regulates all these stages of odontogenesis by coordinating cell proliferation, differentiation, apoptosis, extracellular matrix synthesis and mineral deposition. Molecules that belong mainly to five signalling pathways ensure the molecular dialogue that is used for communication, by epithelial and mesenchymal cells: bone morphogenetic protein (BMP), FGF, sonic hedgehog (Shh), Notch, and Wnt. These pathways involve numerous other molecules such as transcription factors, cytoskeleton proteins, and cell-surface receptors, which regulate gene expression (Cobourne and Mitsiadis, 2006; Mitsiadis and Luder, 2011). A large effort has been made over recent years to understand the molecular and cellular mechanisms leading to tooth pathology. Although much information on the genes that are important for odontogenesis in humans has been revealed using the mouse model, very little is known on the generation of human dental pathologies.

Tooth agenesis is the most frequent developmental malformation within the orofacial complex (Mitsiadis and Luder, 2011; Shimizu and Maeda, 2009). Hypodontia refers to the absence of one to six teeth, oligodontia designates the absence of more than six teeth, and anodontia indicates the absence of all teeth (Shimizu and Maeda, 2009). Prevalence ratios vary considerably between generations and classes of teeth. In total, the prevalence of permanent tooth agenesis ranges from $1.6 \%$ to $9.6 \%$ in the general population, excluding third molars (Vastardis, 2000). Most cases of tooth agenesis are non-syndromic since they occur without developmental defects in other organs (Mitsiadis and Luder, 2011). However, tooth agenesis could be also part of syndromes that affect orofacial tissues such as Down syndrome, cleft lip and palate, and ectodermal dysplasias.

Amelogenesis imperfecta (AI) designates another hereditary developmental malformation that affects the structure and appearance of enamel (Crawford et al., 2007; Mitsiadis and Luder, 2011). In a strict sense, the definition of AI includes only enamel dysplasias, which occur in the absence of defects in other tissues, and can be phenotypically classified into three different types. The hypoplastic type of AI is characterised by a thinner layer of enamel, the hypomaturated form by a rather soft enamel, and the hypocalcified type by an extremely soft enamel that wears quickly after tooth eruption (Crawford et al., 2007).

Beyond these genetic conditions, tooth loss can be caused by common dental diseases such as periodontitis and severe carious lesions, injuries, age-related alterations, and cancer (Marec-Berard et al., 2005; Matalova et al., 2008;
Mitsiadis and Harada, 2015; Mitsiadis and Papagerakis, 2011). For example, in the case of oral squamous cell carcinomas, treatment involves radiotherapy, surgery and chemotherapy. Although more patients are being cured of their disease, a substantial percentage of survivors suffer from significant treatment-related adverse effects. Oral cancers and their treatments often affect the structure and physiological function of more than one orofacial tissues and organs. In particular, radiotherapy and chemotherapy strongly affect salivary gland function, resulting in severe swallowing problems, dental caries and tooth loss (Cooper et al., 1995; Langendijk et al., 2008; Marec-Berard et al., 2005; Matalova et al., 2008; Minicucci et al., 2003).

All these conditions mentioned above affect tooth functionality. Treatment options for patients with tooth agenesis, pathological tooth loss, AI, and other serious defects of dental tissues are based on a constantly increased number of dental biomaterials. Dental implants are used routinely in clinics for the replacement of missing teeth (Adell et al., 1990; Catón et al., 2011; Dodson, 2006). However, these implants are prone to infections, and do not fully re-establish the physiological function of teeth since some essential dental tissues such as the periodontal ligament, which absorbs the shock and balance the mechanical forces during mastication, cannot be formed de novo (Callan, 2007; Catón et al., 2011).

Most of the current therapies of injured or malformed orofacial tissues do not ensure their regeneration and do not lead to a full recovery of their physiological functions. There is therefore a strong need for innovative approaches for the regeneration of missing or pathological tissues and organs of the orofacial complex (Mitsiadis and Harada, 2015).

\section{Stem cell sources for orofacial regeneration}

Cell-based therapies have started to be applied in clinics recently and consist of administration of stem cells, alone or together with scaffolds, to damaged and pathological sites. Stem cells are characterised by the ability to proliferate indefinitely (self-renewal) and to give rise to a large variety of cell types. Therefore, stem cells represent the most promising mediators for successful tissue regeneration. Adult stem cells support tissue homeostasis and repair, in case of injury, throughout life. Various stem cell populations of both mesenchymal and epithelial origin have been identified in exfoliated and adult teeth.

\section{Mesenchymal stem cells}

Mesenchymal stem cells (MSCs) are generally characterised by their ability to differentiate into cartilage, bone and adipose tissues at the single cell level (Mitsiadis et al., 2007; Pittenger, 1999). MSCs isolated from the bone marrow (BMSCs) are the most commonly used for bone regeneration. BMSCs were the first to be used in clinics with success for the treatment of leukaemia since the 1950s (Thomas et al., 1957) and thus constitute the golden standard in stem cell research, including studies aiming to orofacial regeneration. However, BMSCs cells do not have the same embryonic origin as the cells forming the orofacial tissues. Moreover, numerous studies reported that BMSCs differ from MSCs isolated from the orofacial 


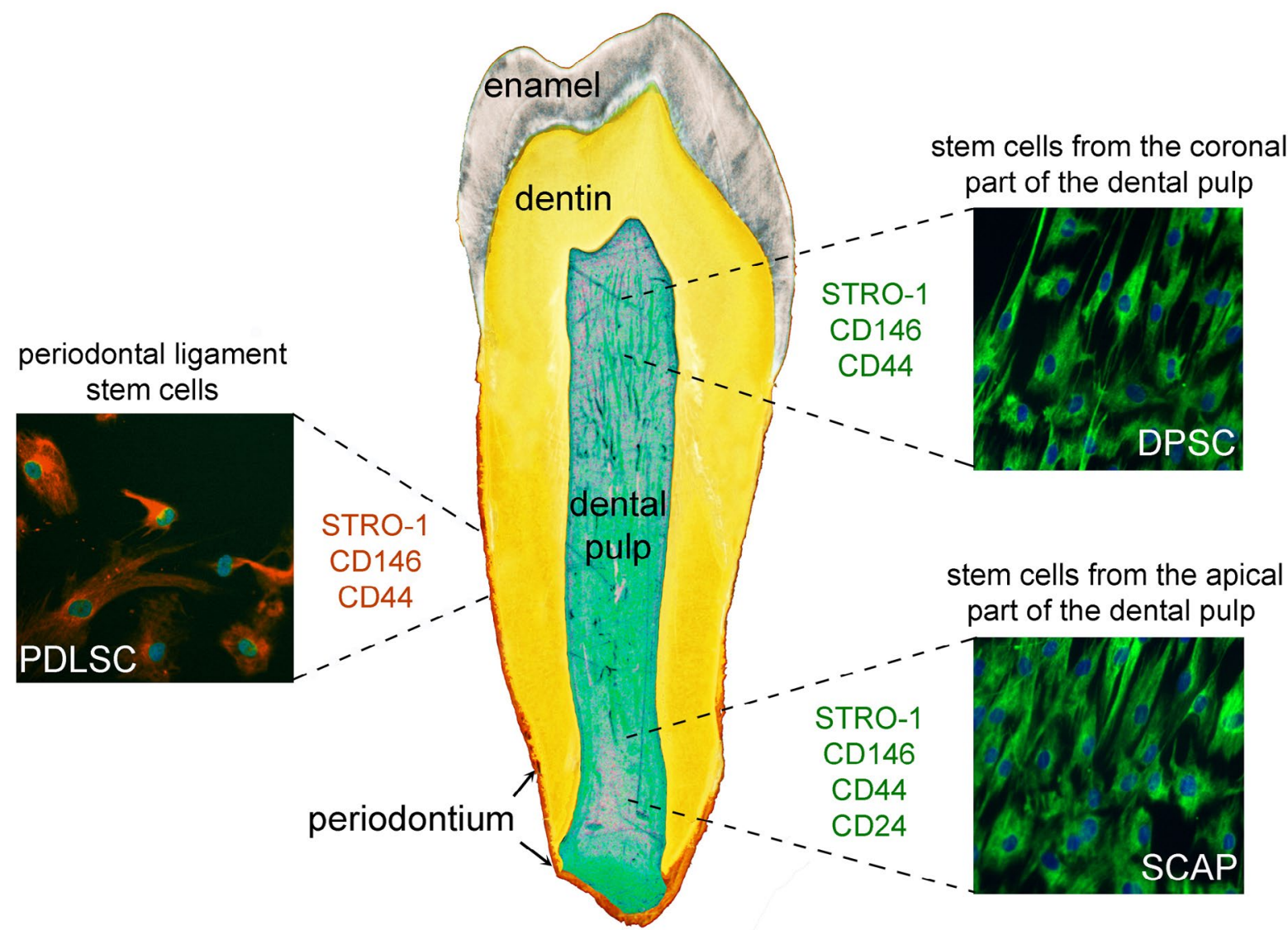

Fig. 2. Main mesenchymal stem cell populations in human teeth and markers for their selection. Green colour: vimentin staining for SCAP and DPSC, Nuclear Mitotic Antigen (NuMA) staining for PDLSC. Red colour: vimentin for PDLSC. Blue colour: DAPI staining for DPSC, SCAP and PDLSC. Abbreviations: DPSC, Dental Pulp Stem Cells; PDLSC, PerioDontal Ligament Stem Cells; SCAP, Stem Cells from the Apical Papilla.

area (Giuliani et al., 2013; Huang et al., 2009; Leucht et al., 2008; La Noce et al., 2014). It has been shown that the embryonic origin of stem cells, combined with their Hox expression profile, play a key role in determining their fate during bone regeneration (Leucht et al., 2008). Indeed, Hox-negative cranial neural crest-derived stem cells adopt a Hox-positive profile and differentiate into osteoblasts after transplantation into the tibia. In contrast, Hox-positive mesoderm-derived stem cells are not able to adopt a Hox-negative profile and differentiate into chondroblasts after transplantation into the mandible (Leucht et al., 2008). These results indicate that stem cell plasticity depends of the embryonic origin of the cells that retain their "positional memory" (Grapin-Botton et $a l ., 1995)$. The use of stem cells originating from cranial neural crest cells is thus important for the regeneration of orofacial tissues and presumably much more appropriate than the use of BMSCs.

A variety of stem cell populations have been identified within the orofacial complex. MSCs have been also isolated from the mandibular bone (Akintoye et al., 2006). Similarly to iliac crest-derived MSCs, stem cells originated from the mandible are clonogenic and exhibit osteogenic potential both in vitro and in vivo. Compared to iliac crest MSCs, mandibular MSCs proliferate more intensively, exhibit delayed senescence and accumulate more calcium in vitro. Their in vivo transplantation results in the formation of a more solid bone when compared to that produced by appendicular MSCs (Mao et al., 2012; Yamaza et al., 2011).

Teeth are sources of quite distinct stem cell types that have been intensively studied during the last decade. Dental mesenchymal stem cells (DMSCs) were the first to be identified in the dental pulp of human permanent teeth (Gronthos et al., 2000). Thereafter, DMSCs have been also isolated from the pulp of exfoliated deciduous teeth, the apical part of dental papilla, the dental follicle, and the periodontal ligament (Fig. 2) (Miura et al., 2003; Seo et al., 2004; Stokowski et al., 2007). Comparative studies have shown that both BMSCs and dental pulp stem cells (DPSCs) have almost identical properties in terms of gene expression and differentiation potential (Dimarino et al., 2013; Gronthos et al., 2000; Phinney and Prockop, 2007). However, DPSCs exhibit higher clonogenic and proliferative potential when compared to BMSCs (Tamaki et al., 2013). DPSCs are able to form odontogenic (Gronthos et al., 2000; Gronthos et al., 2002), adipogenic (Gronthos et al., 2002; Waddington et al., 2009), chondrogenic (Iohara et al., 2006), osteogenic (de Mendonça Costa et al., 2008), myogenic (Seo et al., 2004), and neurogenic (Arthur et al., 2008) lineages in vitro. Moreover, in vivo transplantation of DPSCs mixed with hydroxyapatite/tricalcium phosphate resulted in ectopic pulp-dentin tissue formation (Batouli et al., 2003; Onyekwelu et al., 2007). The first clinical trial of autologous DPSCs transplantation for bone reconstruction 


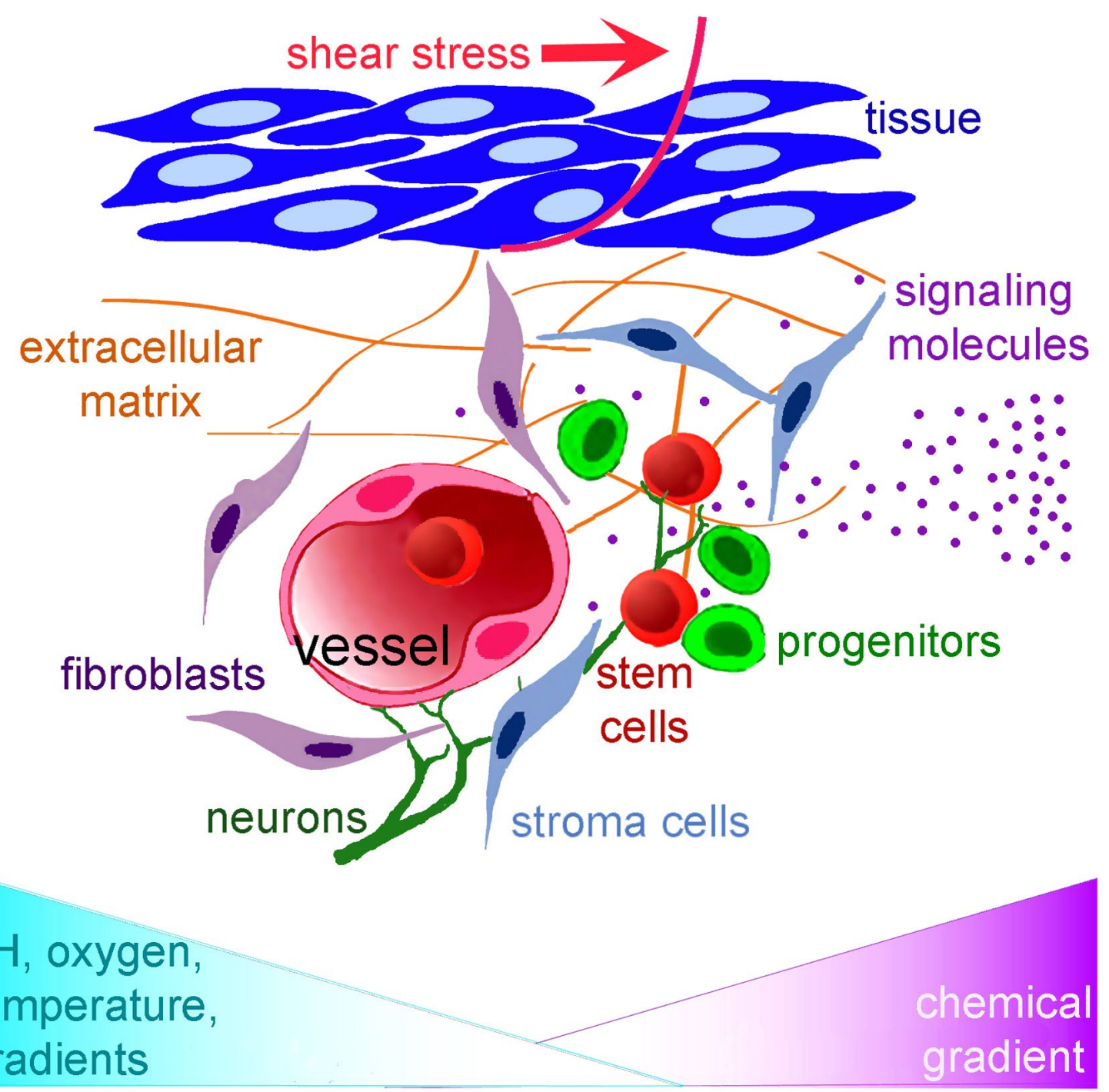

Fig. 3. Schematic representation of the main components of stem cell niches and the main factors affecting stem cells function.

was performed successfully five years ago (D'Aquino et al., 2009; Giuliani et al., 2013).

Exfoliated human deciduous teeth contain a population of multipotent stem cells (SHEDs), which have odontogenic, osteogenic, adipogenic, neurogenic, myogenic, and chondrogenic differentiation potentials (Miura et al., 2003; Seo et al., 2004). In vivo, SHEDs can induce bone and dentin formation (Cordeiro et al., 2008; Miura et al., 2003). Periodontal ligament stem cells (PDLSCs) are able to differentiate into adipogenic and osteogenic cells in vitro (Seo et al., 2004). Upon their transplantation in vivo, PDLSCs are capable of regenerating periodontal tissues, forming thus new cementum and periodontal ligament (Seo et al., 2004; Volponi et al., 2010).

\section{Epithelial stem cells}

Epithelial stem cells (ESCs) from the orofacial complex have been studied in much lesser detail. In the light of oral regeneration, human keratinocytes from the oral mucosa have been isolated and characterised (Izumi et al., 2007). These cells show big and promising potential for the regeneration of the oral mucosa and other orofacial tissues, such as cornea (Nishida et al., 2004) and teeth, since in humans dental ESCs (DESCs) are not present in the crown of the teeth after their eruption. This is the reason why enamel regeneration is impossible after dental injury and carious lesions affect this tissue. Third molars develop postnatally, and thus represent one possible source of DESCs. DECS that have been isolated from unerupted third molars displaying odontogenic potential (Honda et al., 2005; Young et al., 2002). The epithelial rests of Mallasez (ERM), located in proximity to the tooth root, represent another possible source of DESCs (Mitsiadis and Harada, 2015; Mitsiadis and Papagerakis, 2011; Otsu et al., 2014). These cells are remnants of the dental epithelium and express several ESCs markers such as Bmi1, p75, and Nanog.

\section{Stem cell niches}

The behaviour of the stem cells depends on the combination of cellular, molecular, and physical conditions of their microenvironment, also called the stem cell niche (Mitsiadis et al., 2007) (Fig. 3). Paracrine and autocrine soluble cues secreted in the stem cell niche and physical factors such 
view from the top

cross-sectional view

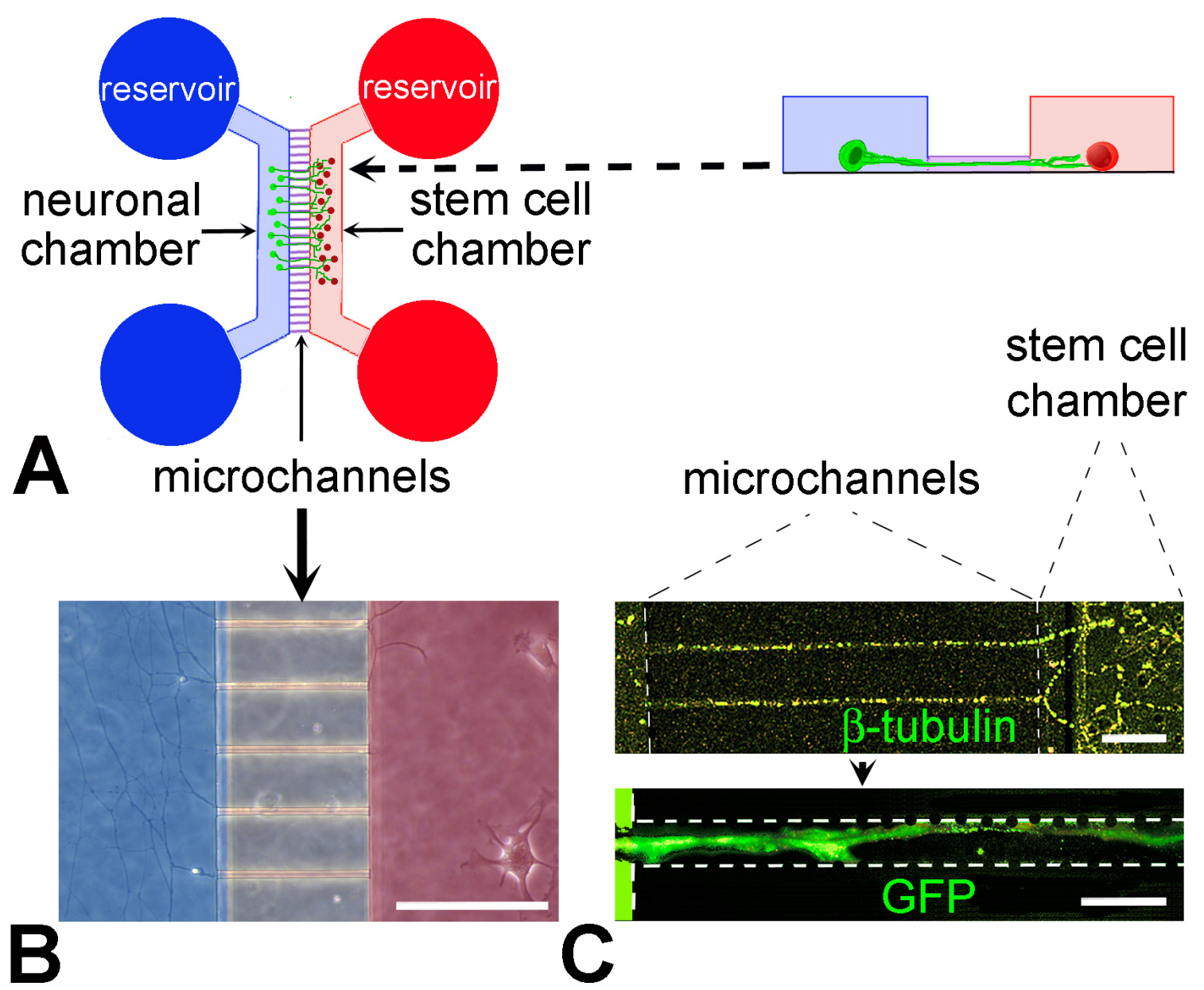

Fig. 4. Microfluidic co-culture systems for the study of the interactions between innervation and target tissues or cells. A) Schematic representation of the co-culture system: neurons and target cells cultured in different chambers, while axons can grow from the neuronal chamber to the stem cell chamber through the microchannels. The different culture media (i.e. blue and red) remain separated. B) Bright field image of the microchannels. Blue artificial colour: neuronal chamber; purple artificial colour: stem cells chamber. C) Immunofluorescent staining of single axonal fibres within the microchannels at different magnifications. Scale bars: $\mathbf{B}=100 \mu \mathrm{m} ; \mathbf{C}$ upper $=25 \mu \mathrm{m} ; \mathbf{C}$ lower $=10 \mu \mathrm{m}$.

as stiffness, topography and shear stress all regulate stem cell behaviour (de Souza, 2012). In particular, this highly regulated microenvironment maintains and regulates the balance between stem cell self-renewal and differentiation (Jones and Wagers, 2008). Stromal support cells of the niche interact directly with the stem cells and with each other via cell-surface molecules, gap junctions and secreted factors. The extracellular matrix (ECM) provides structure and organisation to the niche, and conveys mechanical signals that play a key role in the differentiation of stem cells. Moreover, ECM molecules interact directly with stem and stromal cells, playing an active role in the regulation of their behaviour. Blood vessels carry systematic signals, such as endocrine molecules, nutrients and inflammatory cells. Moreover, circulating haematopoietic stem cells reach stem cell niches via blood vessels, following gradients of molecular signals (Jones and Wagers, 2008). Increasing evidence supports the notion that innervation also plays an active role in regulating differentiation and mobilisation of stem cells (Jones and Wagers, 2008; Pagella et al., 2014a). In the orofacial region, innervation is strictly required for salivary gland morphogenesis (Knox et al., 2010; Pagella et al., 2014a) and taste buds development and maintenance (Oakley and Witt, 2004; Pagella et al., 2014a). In teeth, it was recently shown that secretion of Shh by a neurovascular bundle niche regulates mesenchymal stem cells homeostasis in the mouse incisor (Zhao et al., 2014).

Therefore, since stem cell niches regulate many aspects of stem cell functions, the elucidation of their composition and roles in healthy and pathological conditions has become a pressing issue in regenerative medicine. Understanding how all components of the niches influence stem cell behaviour and fate is necessary for the development of successful therapies aiming to entirely regenerate tissues and organs.

Studying stem cell niches in vivo is challenging, since it is very difficult to estimate and predict the contribution of their various constituents and single factors to stem cell 


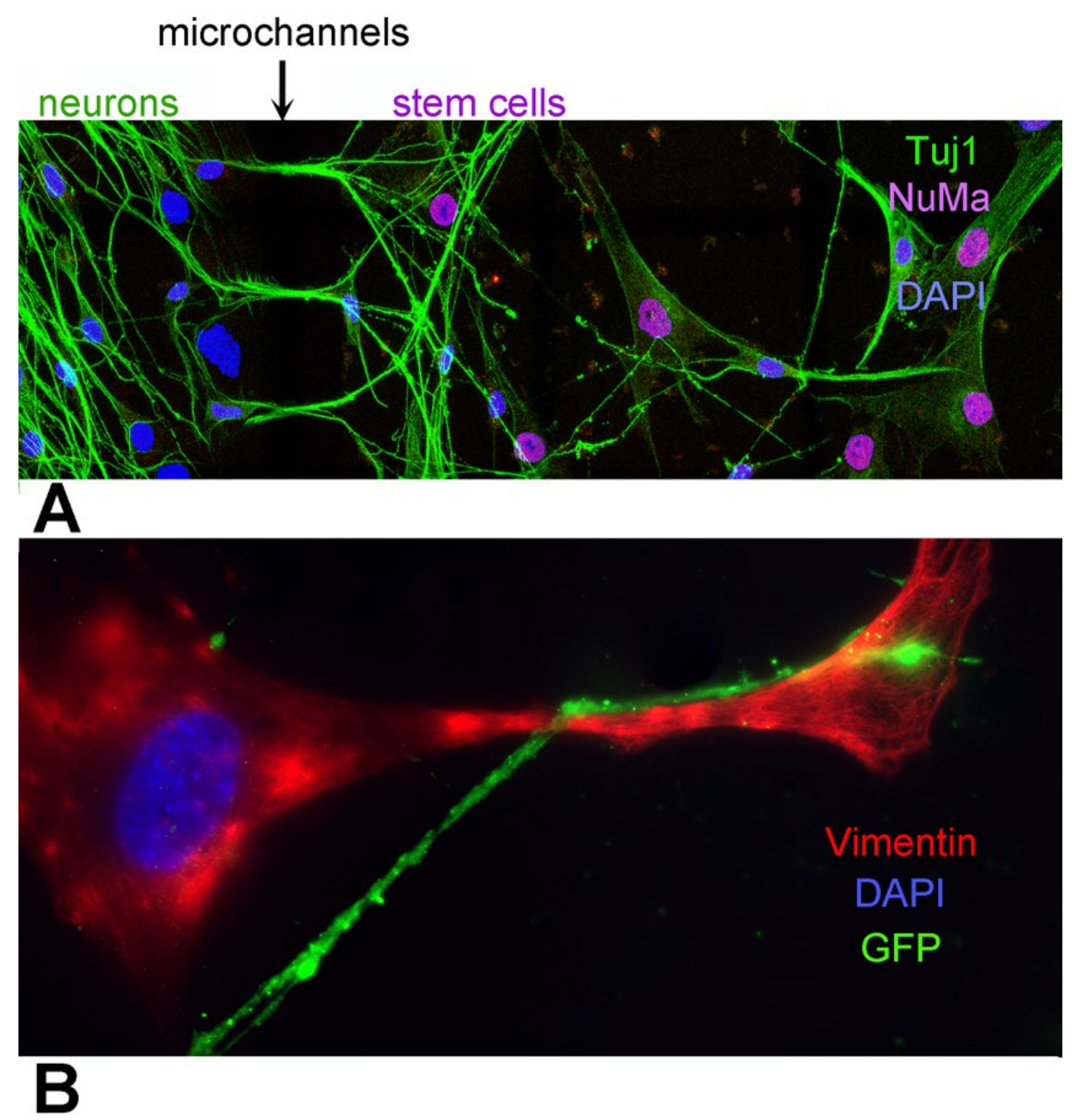

Fig. 5. Example of co-culture of mouse trigeminal ganglia and human stem cells. A) Mouse sensory neurons (blue nucleus, green cytoskeleton) grow axons through the microchannels and contact human mesenchymal stem cells (purple nucleus, green cytoskeleton) (green colour: $\beta$-tubulin; red colour: NuMA; blue colour: DAPI). B) Example of high magnification image of co-cultured trigeminal neurons (green colour: green fluorescence protein) and stem cells (red colour: vimentin; blue colour: DAPI).

behaviour. Multiple growth factors and specific culture medium are needed to culture stem cells in vitro. These supplements are normally costly, and conventional in vitro culture setups normally poorly assess the precise control of spatiotemporal cues, have low reproducibility and low inputs of mechanical and physical proprieties (Chung et al., 2005; Gupta et al., 2010; Lesher-Perez et al., 2013).

To overcome these difficulties, significant efforts have been made recently to develop methods that allow the study of stem cell niches both in vitro and in vivo. In this context, microfluidic systems represent one of the most promising approaches for the modelling of stem cell niches and the study of the factors that regulate stem cell behaviour. Microfluidic technology provides unprecedented control over the local environment of cells and can be used to overcome difficulties related to traditional stem cell culture methods.

\section{Microfluidics for stem cell niches modelling}

Microfluidic systems manipulate small amounts of fluids using channels with dimensions of 10-100 $\mu \mathrm{m}$, thus offering new capabilities in the control of concentrations of molecules in space and time (Whitesides, 2006). These labon-chip technologies offer inexpensive cell analysis tools, capable of testing single cells or cell populations under controlled and reproducible conditions. Microfluidics are important tools for stem cell analysis, by providing tempospatial control over cell growth and stimuli by combining specific surfaces with regulated transport of soluble factors. Therefore, microfluidic platforms allow the miniaturisation and mimicking of the complex microenvironment of stem cell niches, thus providing a better control of variations within the niches in a high throughput and scalable manner (Titmarsh et al., 2014). The newest technological developments led to the improvement of these microfluidic 
devices that could also be used for the analysis and screening of chemical and mechanical factors affecting stem cell niches (Ankam et al., 2013; Gupta et al., 2010). Microfluidic devices are currently being developed, with the goal of mimicking all the components that regulate stem cell niche physiology.

In order to investigate the roles of soluble factors and gradients within stem cell niches, microfluidic gradient generators have been used to assess the dependence of stem cell differentiation and chemotaxis on growth factors, using a single device (Xu et al., 2013). In vivo, stem cell niches are exposed to local gradients of several diffusible factors, which represent a further challenge for successfully mimicking the niches. Recently developed, microfluidic systems allow the generation and maintenance of multiple gradients along different directions, thus providing a first step towards the modelling of complex gradients combinations in vitro (Xu and Heilshorn, 2013). Chemical gradient-based microfluidics are also used to understand homing mechanisms and responsiveness to soluble factors, which are intimately coordinated with the motile and recruitment capability of the stem cells (Wu et al., 2013).

Stem cells physiology strongly depends on cell-cell contacts and contacts between cells and the ECM. It is therefore crucial to design adequate cell culture substrates through surface patterning. Indeed, devices equipped with microfluidic gradient generators allow the immobilisation of precise concentrations of cell adhesion motifs (Liu et al., 2012). In this direction, it is also possible to create patterns of different cell types and ECM components within a single culture system by using microfluidic mixing of cell-laden hydrogels (Mahadik et al., 2014). Mechanical strain is an important factor that can foster stem cell differentiation towards osteogenic, chondrogenic, muscular and endothelial lineages (Ertl et al., 2014). Deformable materials such as hydrogels allow the application of defined shear forces and the uniform addition of reagents. Furthermore, hydrogels can be inserted into the microchambers to provide a soft $3 \mathrm{D}$ environment for stem cells (Ertl et al., 2014). In addition, microfluidic devices combined with atomic force microscopy techniques can be used for studying the effects of mechanical stress on stem cell behaviour (Magdesian et al., 2012).

Hypoxic conditions, which play a crucial role in stem cell physiology, can be created in the microfluidic devices by combination of gas-tight substrates with de-aerated media.

Microfluidic technology can be applied for studying the interactions between neurons and different populations of stem cells during the process of orofacial tissue regeneration. Nerve fibres have essential roles in stem cell behaviour in almost all tissues and organs (Brownell et al., 2011; Fitch et al., 2012; Knox et al., 2010), but the mechanisms underlying neurons-stem cells interactions are still poorly understood.

Co-cultures constitute a valuable method to investigate and manipulate the interactions between nerve fibres and target tissues in a controlled and isolated environment. However, co-culturing is subject to various technical adjustments. In vivo neurons contact their targets, including stem cell niches, through their axons, while their bodies (soma) are located in different compartments, such as ganglia. This organisation is reflected in the different media requirements for the in vitro cultures of neurons and their target tissues.

We have recently studied the pattern of innervation of developing tooth germs from different developmental stages in a microfluidic co-culture system (Fig. 4) (Pagella et al., 2014b). This system permits the culture of neuronal bodies and dental tissues in two separated compartments (chambers) with different culture media; however, allowing the passage of axons from the one culture chamber to the other (Fig. 4). We have demonstrated that in this system, both trigeminal nerve fibres and tooth germs can be cultured in optimal conditions for at least 10 days (Pagella et al., 2014b).

We have also used this microfluidic system to coculture dorsal root ganglia and osteoblasts (Neto et $a l ., 2014)$, as well as trigeminal sensory neurons and mesenchymal stem cells (Fig. 4 and 5). In these conditions, both neurons and stem cells maintain their physiological properties to a greater extent than in conventional cocultures, thus providing in vivo representative conditions. Microfluidic systems allow easy imaging of single stem cells and their interaction with axonal projections (Fig. 4 and 5). In addition, these devices can be used for analysing the effects of molecules on neuronal and stem cell behaviour. Therefore, microfluidic platforms offer realistic in vitro scenarios to pursue and comprehend the orchestrated cues that stem cells undergo during all steps of tissue regeneration. The great potential of stem cells in regenerative approaches is boosted by new automated and miniaturised technologies that allow to better model the in vivo stem cell microenvironment (Ertl et al., 2014).

\section{Perspectives}

Stem cells-mediated regenerative therapies represent the most promising approach in the light of the restoration of orofacial tissues following traumas, tumours or genetic disorders. For this purpose, precise understanding of the exact mechanisms underlying the behaviour of stem cells is fundamental. In this context, increasing evidence supports the notion that innervation plays a fundamental role in the physiology of stem cells and in tissue regeneration, and is essential for the functioning of the different organs. It is therefore necessary to provide organs with proper innervation following reparative surgery, an aspect that is often neglected in clinical practice. Microfluidic devices could be of help since they allow accurate manipulation of the microenvironment and detailed investigation of various physiological processes at the single cell level. In particular, the use of microfluidics represents an extremely valuable tool to identify the exact mechanisms underlying the crosstalk between nerve fibres and stem cells and their niches during regenerative processes. This will significantly facilitate the development of effective and more appropriated therapies that would fully restore functionality of damaged and pathological tissues and organs of the orofacial complex. 


\section{Acknowledgments}

This work was supported by funds of the University of Zurich and by COST (Cost Action NAMABIO MP1005, COST-STSM-MP1005-14287). All authors contributed to the planning, writing, critical reading, and editing of the present manuscript. The authors confirm that there are no conflicts of interest associated with this work.

\section{References}

Adell R, Eriksson B, Lekholm U, Brånemark PI, Jemt $\mathrm{T}$ (1990) Long-term follow-up study of osseointegrated implants in the treatment of totally edentulous jaws. Int $\mathrm{J}$ Oral Maxillofac Implants 5: 347-359.

Akintoye SO, Lam T, Shi S, Brahim J, Collins MT, Robey PG (2006) Skeletal site-specific characterization of orofacial and iliac crest human bone marrow stromal cells in same individuals. Bone 38: 758-768.

Ankam S, Teo BKK, Kukumberg M, Yim EKF (2013) High throughput screening to investigate the interaction of stem cells with their extracellular microenvironment. Organogenesis 9: 128-142.

Arthur A, Rychkov G, Shi S, Koblar SA, Gronthos S (2008) Adult human dental pulp stem cells differentiate toward functionally active neurons under appropriate environmental cues. Stem Cells 26: 1787-1795.

Batouli S, Miura M, Brahim J, Tsutsui TW, Fisher LW, Gronthos S, Gehron Robey P, Shi S (2003) Comparison of stem-cell-mediated osteogenesis and dentinogenesis. J Dent Res 82: 976-981.

Bonaiti C, Briard ML, Feingold J, Pavy B, Psaume J (1982) An epidemiological and genetic study of facial clefting in France. I Epidemiology and frequency in relatives. J Med Genet 19: 8-15.

Brownell I, Guevara E, Bai CB, Loomis CA, Joyner AL (2011) Nerve-derived sonic hedgehog defines a niche for hair follicle stem cells capable of becoming epidermal stem cells. Cell Stem Cell 8: 552-565.

Callan DP (2007) Dental implant design and oral and systemic health. Compend Contin Educ Dent 28: 482-484, 486-490, 492.

Catón J, Bostanci N, Remboutsika E, De Bari C, Mitsiadis TA (2011) Future dentistry: cell therapy meets tooth and periodontal repair and regeneration. J Cell Mol Med 15: 1054-1065.

Chung BG, Flanagan LA, Rhee SW, Schwartz PH, Lee AP, Monuki ES, Jeon NL (2005) Human neural stem cell growth and differentiation in a gradient-generating microfluidic device. Lab Chip 5: 401-406.

Cobourne MT (2004) The complex genetics of cleft lip and palate. Eur J Orthod 26: 7-16.

Cobourne MT, Mitsiadis T (2006) Neural crest cells and patterning of the mammalian dentition. J Exp Zool B Mol Dev Evol 306: 2512660.

Cooper JS, Fu K, Marks J, Silverman S (1995) Late effects of radiation therapy in the head and neck region. Int J Radiat Oncol Biol Phys 31: 1141-1164.

Cordeiro MM, Dong Z, Kaneko T, Zhang Z, Miyazawa M, Shi S, Smith AJ, Nör JE (2008) Dental pulp tissue engineering with stem cells from exfoliated deciduous teeth. J Endod 34: 962-969.

Crawford PJM, Aldred M, Bloch-Zupan A (2007) Amelogenesis imperfecta. Orphanet J Rare Dis 2: 17. doi:10.1186/1750-1172-2-17.

D’Aquino R, De Rosa A, Lanza V, Tirino V, Laino L, Graziano A, Desiderio V, Laino G, Papaccio G (2009) Human mandible bone defect repair by the grafting of dental pulp stem/progenitor cells and collagen sponge biocomplexes. Eur Cells Mater 18: 75-83.

Dimarino AM, Caplan AI, Bonfield TL (2013) Mesenchymal stem cells in tissue repair. Front Immunol 4: 201. doi:10.3389/fimmu.2013.00201.

Dixon MJ, Marazita ML, Beaty TH, Murray JC (2011) Cleft lip and palate: understanding genetic and environmental influences. Nat Rev Genet 12: 167-178.

Djouad F, Bouffi C, Ghannam S, Noël D, Jorgensen C (2009) Mesenchymal stem cells: innovative therapeutic tools for rheumatic diseases. Nat Rev Rheumatol 5: 392399.

Dodson TB (2006) Predictors of dental implant survival. J Massachusetts Dent Soc 54: 34-38.

Ertl P, Sticker D, Charwat V, Kasper C, Lepperdinger G (2014) Lab-on-a-chip technologies for stem cell analysis. Trends Biotechnol 32: 245-253.

Fitch SR, Kimber GM, Wilson NK, Parker A, Mirshekar-Syahkal B, Göttgens B, Medvinsky A, Dzierzak E, Ottersbach K (2012) Signaling from the sympathetic nervous system regulates hematopoietic stem cell emergence during embryogenesis. Cell Stem Cell 11: 554566.

Giuliani A, Manescu A, Langer M, Rustichelli F, Desiderio V, Paino F, De Rosa A, Laino L, D’Aquino R, Tirino V, Papaccio G (2013) Three years after transplants in human mandibles, histological and in-line holotomography revealed that stem cells regenerated a compact rather than a spongy bone: biological and clinical implications. Stem Cells Transl Med 2: 316-324.

Goodacre T, Swan MC (2008) Cleft lip and palate: current management. Paediatr Child Health (Oxford) 18: 283-292.

Grapin-Botton A, Bonnin MA, McNaughton LA, Krumlauf R, Le Douarin NM (1995) Plasticity of transposed rhombomeres: Hox gene induction is correlated with phenotypic modifications. Development 121: $2707-$ 2721.

Gronthos S, Mankani M, Brahim J, Robey PG, Shi S (2000) Postnatal human dental pulp stem cells (DPSCs) in vitro and in vivo. Proc Natl Acad Sci USA 97: 1362513630.

Gronthos S, Brahim J, Li W, Fisher LW, Cherman N, Boyde A, DenBesten P, Robey PG, Shi S (2002) Stem cell properties of human dental pulp stem cells. J Dent Res 81: 531-535.

Gupta K, Kim D-H, Ellison D, Smith C, Kundu A, Tuan J, Suh K-Y, Levchenko A (2010) Lab-on-a-chip devices as an emerging platform for stem cell biology. Lab Chip 10: 2019-2031.

Handrigan GR, Buchtová M, Richman JM (2007) Gene discovery in craniofacial development and disease - cashing in your chips. Clin Genet 71: 109-119. 
Honda M, Sumita Y, Kagami H, Ueda M (2005) Histological and immunohistochemical studies of tissue engineered odontogenesis. Arch Histol Cytol 68: 89-101.

Huang GT-J, Gronthos S, Shi S (2009) Mesenchymal stem cells derived from dental tissues $v s$. those from other sources: their biology and role in regenerative medicine. J Dent Res 88: 792-806.

Iohara K, Zheng L, Ito M, Tomokiyo A, Matsushita K, Nakashima M (2006) Side population cells isolated from porcine dental pulp tissue with self-renewal and multipotency for dentinogenesis, chondrogenesis, adipogenesis, and neurogenesis. Stem Cells 24: 2493-2503.

Izumi K, Tobita T, Feinberg SE (2007) Isolation of human oral keratinocyte progenitor/stem cells. J Dent Res 86: $341-346$.

Jones DL, Wagers AJ (2008) No place like home: anatomy and function of the stem cell niche. Nat Rev Mol Cell Biol 9: 11-21.

Knox SM, Lombaert IM, Reed X, Vitale-Cross L, Gutkind JS, Hoffman MP (2010) Parasympathetic innervation maintains epithelial progenitor cells during salivary organogenesis. Science 329: 1645-1647.

Kouskoura T, Fragou N, Alexiou M, John N, Sommer L, Graf D, Katsaros C, Mitsiadis TA (2011) The genetic basis of craniofacial and dental abnormalities. Schweiz Monatsschr Zahnmed 121: 636-646.

Langendijk JA, Doornaert P, Verdonck-de Leeuw IM, Leemans CR, Aaronson NK, Slotman BJ (2008) Impact of late treatment-related toxicity on quality of life among patients with head and neck cancer treated with radiotherapy. J Clin Oncol 26: 3770-3776.

Lesher-Perez SC, Frampton JP, Takayama S (2013) Microfluidic systems: a new toolbox for pluripotent stem cells. Biotechnol J 8: 180-191.

Leucht P, Kim J-B, Amasha R, James AW, Girod S, Helms JA (2008) Embryonic origin and Hox status determine progenitor cell fate during adult bone regeneration. Development 135: 2845-2854.

Liu Z, Xiao L, Xu B, Zhang Y, Mak AF, Li Y, Man W-Y, Yang M (2012) Covalently immobilized biomolecule gradient on hydrogel surface using a gradient generating microfluidic device for a quantitative mesenchymal stem cell study. Biomicrofluidics 6: 024111. doi: 10.1063/1.4704522.

Lumsden AGS (1988) Spatial organization of the epithelium and the role of neural crest cells in the initiation of the mammalian tooth germ. Development 103: 155-169.

Magdesian MH, Sanchez FS, Lopez M, Thostrup P, Durisic N, Belkaid W, Liazoghli D, Grütter P, Colman DR (2012) Atomic force microscopy reveals important differences in axonal resistance to injury. Biophys J 103: 405-414.

Mahadik BP, Wheeler TD, Skertich LJ, Kenis PJA, Harley BAC (2014) Microfluidic generation of gradient hydrogels to modulate hematopoietic stem cell culture environment. Adv Healthc Mater 3: 449-458.

Mao JJ, Robey PG, Prockop DJ (2012) Stem cells in the face: tooth regeneration and beyond. Cell Stem Cell 11: 291-301.

Marec-Berard P, Azzi D, Chaux-Bodard AG, Lagrange H, Gourmet R, Bergeron C (2005) Long-term effects of chemotherapy on dental status in children treated for nephroblastoma. Pediatr Hematol Oncol 22: 581-588.

Matalova E, Fleischmannova J, Sharpe PT, Tucker AS (2008) Tooth agenesis: from molecular genetics to molecular dentistry. J Dent Res 87: 617-623.

De Mendonça Costa A, Bueno DF, Martins MT, Kerkis I, Kerkis A, Fanganiello RD, Cerruti H, Alonso N, PassosBueno MR (2008) Reconstruction of large cranial defects in nonimmunosuppressed experimental design with human dental pulp stem cells. J Craniofac Surg 19: 204-210.

Minicucci EM, Lopes LF, Crocci AJ (2003) Dental abnormalities in children after chemotherapy treatment for acute lymphoid leukemia. Leuk Res 27: 45-50.

Minoux M, Rijli FM (2010) Molecular mechanisms of cranial neural crest cell migration and patterning in craniofacial development. Development 137: 2605-2621.

Mitsiadis TA, Luder HU (2011) Genetic basis for tooth malformations: from mice to men and back again. Clin Genet 80: 319-329.

Mitsiadis TA, Graf D (2009) Cell fate determination during tooth development and regeneration. Birth Defects Res C Embryo Today 87: 199-211.

Mitsiadis TA, Woloszyk A, Jiménez-Rojo L (2012) Nanodentistry: combining nanostructured materials and stem cells for dental tissue regeneration. Nanomedicine (Lond). 7: 1743-1753.

Mitsiadis TA (2011) Everything is on the head. Front Physiol 2: 2. doi:10.3389/fphys.2011.00002.

Mitsiadis TA, Barrandon O, Rochat A, Barrandon Y, De Bari C (2007) Stem cell niches in mammals. Exp Cell Res 313: 3377-3385.

Mitsiadis TA, Harada H (2015) Regenerated teeth: the future of tooth replacement. An update. Regen Med 10: 5-8.

Mitsiadis TA, Papagerakis P (2011) Regenerated teeth: the future of tooth replacement? Regen Med 6: 135-139.

Miura M, Gronthos S, Zhao M, Lu B, Fisher LW, Robey PG, Shi S (2003) SHED: stem cells from human exfoliated deciduous teeth. Proc Natl Acad Sci USA 100: 5807-5812.

Neto E, Alves CJ, Sousa DM, Alencastre IS, Lourenço AH, Leitão L, Ryu HR, Jeon NL, Fernandes R, Aguiar P, Almeida RD, Lamghari M (2014) Sensory neurons and osteoblasts: close partners in a microfluidic platform. Integr Biol (Camb) 6: 586-595.

Nishida K, Yamato M, Hayashida Y, Watanabe K, Yamamoto K, Adachi E, Nagai S, Kikuchi A, Maeda N, Watanabe H, Okano T, Tano Y (2004) Corneal reconstruction with tissue-engineered cell sheets composed of autologous oral mucosal epithelium. N Engl J Med 351: 1187-1196.

La Noce M, Paino F, Spina A, Naddeo P, Montella R, Desiderio V, De Rosa A, Papaccio G, Tirino V, Laino L (2014) Dental pulp stem cells: state of the art and suggestions for a true translation of research into therapy. J Dent 42: 761-768.

Oakley B, Witt M (2004) Building sensory receptors on the tongue. J Neurocytol 33: 631-646.

Onyekwelu O, Seppala M, Zoupa M, Cobourne MT (2007) Tooth development: 2. Regenerating teeth in the laboratory. Dent Update 34: 20-22, 25-26, 29. 
Otsu K, Kumakami-Sakano M, Fujiwara N, Kikuchi K, Keller L, Lesot H, Harada H (2014) Stem cell sources for tooth regeneration: current status and future prospects. Front Physiol 5: 36. doi:10.3389/fphys.2014.00036.

Pagella P, Jiménez-Rojo L, Mitsiadis TA (2014a) Roles of innervation in developing and regenerating orofacial tissues. Cell Mol Life Sci 71: 2241-2251.

Pagella P, Neto E, Jiménez-Rojo L, Lamghari M, Mitsiadis TA (2014b) Microfluidics co-culture systems for studying tooth innervation. Front Physiol 5: 326. doi:10.3389/fphys.2014.00326.

Papadopoulos NA, Papadopoulos MA, Kovacs L, Zeilhofer HF, Henke J, Boettcher P, Biemer E (2005) Foetal surgery and cleft lip and palate: current status and new perspectives. Br J Plast Surg 58: 593-607.

Phinney DG, Prockop DJ (2007) Concise review: mesenchymal stem/multipotent stromal cells: the state of transdifferentiation and modes of tissue repair - current views. Stem Cells 25: 2896-2902.

Pittenger MF (1999) Multilineage potential of adult human mesenchymal stem cells Science 284: 143-147.

Scadden DT (2006) The stem-cell niche as an entity of action. Nature 441: 1075-1079.

Scheller EL, Krebsbach PH, Kohn DH (2009) Tissue engineering: state of the art in oral rehabilitation. J Oral Rehabil 36: 368-389.

Seo B-M, Miura M, Gronthos S, Bartold PM, Batouli S, Brahim J, Young M, Robey PG, Wang C-Y, Shi S (2004) Investigation of multipotent postnatal stem cells from human periodontal ligament. Lancet 364: 149-155.

Shimizu T, Maeda T (2009) Prevalence and genetic basis of tooth agenesis. Jpn Dent Sci Rev 45: 52-58.

De Souza N (2012) In vitro niches. Nat Methods 10 : 37-37.

Stokowski A, Shi S, Sun T, Bartold PM, Koblar SA, Gronthos S (2007) EphB/ephrin-B interaction mediates adult stem cell attachment, spreading, and migration: implications for dental tissue repair. Stem Cells 25: 156164.

Tamaki Y, Nakahara T, Ishikawa H, Sato S (2013) In vitro analysis of mesenchymal stem cells derived from human teeth and bone marrow. Odontology 101: 121-132.

Thomas ED, Lochte HL, Lu WC, Ferrebee JW (1957) Intravenous infusion of bone marrow in patients receiving radiation and chemotherapy. N Engl J Med 257: 491-496.
Titmarsh DM, Chen H, Glass NR, Cooper-White JJ (2014) Concise review: microfluidic technology platforms: poised to accelerate development and translation of stem cell-derived therapies. Stem Cells Transl Med 3: 81-90.

Vastardis H (2000) The genetics of human tooth agenesis: new discoveries for understanding dental anomalies. Am J Orthod Dentofacial Orthop 117: 650-656.

Volponi AA, Pang Y, Sharpe PT (2010) Stem cell-based biological tooth repair and regeneration. Trends Cell Biol 20: 715-722.

Waddington RJ, Youde SJ, Lee CP, Sloan AJ (2009) Isolation of distinct progenitor stem cell populations from dental pulp. Cells Tissues Organs 189: 268-274.

Whitesides GM (2006) The origins and the future of microfluidics. Nature 442: 368-373.

Wu J, Wu X, Lin F (2013) Recent developments in microfluidics-based chemotaxis studies. Lab Chip 13: 2484-2499.

Xu B-Y, Hu S-W, Qian G-S, Xu J-J, Chen H-Y (2013) A novel microfluidic platform with stable concentration gradient for on chip cell culture and screening assays. Lab Chip 13: 3714-3720.

Xu H, Heilshorn SC (2013) Microfluidic investigation of BDNF-enhanced neural stem cell chemotaxis in CXCL12 gradients. Small 9: 585-595.

Yamaza T, Ren G, Akiyama K, Chen C, Shi Y, Shi S (2011) Mouse mandible contains distinctive mesenchymal stem cells. J Dent Res 90: 317-324.

Young CS, Terada S, Vacanti JP, Honda M, Bartlett JD, Yelick PC (2002) Tissue engineering of complex tooth structures on biodegradable polymer scaffolds. J Dent Res 81: $695-700$.

Zhao H, Feng J, Seidel K, Shi S, Klein O, Sharpe P, Chai Y (2014) Secretion of shh by a neurovascular bundle niche supports mesenchymal stem cell homeostasis in the adult mouse incisor. Cell Stem Cell 14: 160-173.

\section{Editor's Note}

All questions/comments by the reviewers were answered by text changes. There is hence no Discussion with Reviewers section. 